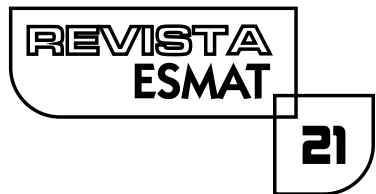

\title{
O RECONHECIMENTO DA FILIAÇÃO SOCIOAFETIVA E DA MULTIPARENTALIDADE NO REGISTRO CIVIL BRASILEIRO À LUZ DOS PRINCÍPIOS QUE REGEM O DIREITO DE FAMÍLIA
}

THE RECOGNITION OF SOCIAL-AFFECTIVE PARENTHOOD AND MULTIPARENTHOOD IN THE BRAZILIAN CIVIL REGISTER IN LIGHT OF THE

PRINCIPLES THAT REGULATE FAMILY LAWY

Flávia Roberta de Gusmão Oliveira

Doutoranda em Direito, pela Universidade Católica de Pernambuco (UNICAP). Mestra em Direitos Humanos, pela Universidade Federal de Pernambuco (UFPE). Bacharela em Direito, pela Universidade Católica de Pernambuco (UNICAP). E-mail: betagusmao@gmail.com.

Vera Lúcia da Silva Cabral

Advogada. Especialista em Gestão Ambiental e em Educação. Mestra em Educação e em Gestão Empresarial, pelo Centro Universitário UNIFBVMYDEN.

\section{RESUMO}

Recentemente, o Conselho Nacional de Justiça (CNJ), por meio do Provimento $n^{\circ} 63$, regulamentou o reconhecimento da filiação socioafetiva no Registro Civil, desburocratizando os casos de reconhecimento da filiação com base na afetividade, bem como permitiu a multiparentalidade. Tal inovação coaduna-se com o arcabouço principiológico do direito de família brasileiro, em especial com os princípios da afetividade, da dignidade da pessoa humana e do melhor interesse da criança. Dessa maneira, o presente estudo teve por objetivo analisar o papel do reconhecimento da filiação socioafetiva e da multiparentalidade no registro civil brasileiro, à luz dos princípios que regem o direito de família. Metodologicamente, utilizamos a abordagem qualitativa. Já o método de pesquisa adotado foi o dialético, e as técnicas de coleta de dados foram a documental e o estudo bibliográfico. Nossos resultados apontam que o Provimento $n^{\circ} 63$ do Conselho Nacional de Justiça, de 2017, representou um marco para o direito de família brasileiro, uma vez que possibilitou a regularização e o reconhecimento de situações fáticas de arranjos familiares diversos, com base na afetividade.

PALAVRAS-CHAVE: Multiparentalidade. Afetividade. Arranjos Familiares. Registro Civil. 


\section{ABSTRACT}

Recently, the National Council of Justice (CNJ), through Provision No. 63, regulated the recognition of socio-affective affiliation in the Civil Registry, bureaucratizing the cases of recognition of the affiliation based on the affectivity, as well as allowed multiparentality. Such an innovation is consistent with the principiological framework of Brazilian family law, especially with the principles of affection, the dignity of the human person and the best interest of the child. Thus, the present study aimed to analyze the role of recognition of socio-affective affiliation and multiparentality in the Brazilian civil registry, in light of the principles that govern family law. Methodologically we use the qualitative approach. Already the method of research adopted was the dialectic and the techniques of data collection were: bibliographic and documentary. Our results indicate that the CNJ's provision 63/2017 represented a milestone for Brazilian family law, since it allowed the regularization and recognition of factual situations of diverse family arrangements, based on affectivity.

KEYWORDS: Multiparentality. Affectivity. Family Arrangements. Civil Registry.

\section{INTRODUÇÃO}

A formação da família passou por várias alterações ao longo das épocas; por muito tempo foi mantido o modelo familiar patriarcal e matrimonial, ou seja, aquele formado de acordo com os padrões sociais estabelecidos pela sociedade. Essa família era originada pelo casamento, por isso, considerada legítima, pois formada pela união de um homem com uma mulher, daí gerando os filhos. Esse formato familiar tinha como base a hierarquia, o patrimônio e o individualismo, não se considerava a afetividade como base propulsora da formação familiar.

O Código Civil, de 1916, amparava esse formato de família e admitia a separação judicial e o desquite para desfazê-la. Assim, até o século $X X$, qualquer outra modalidade de família, que não fosse a legítima, não era reconhecida e, dessa forma, ficava à margem da sociedade.

Mas a realidade era diferente do que propunha a normatização. Existiam várias famílias formadas sem ser pelo matrimônio. E o Estado foi obrigado a reconhecê-las, daí começou a surgir a proteção aos filhos concebidos fora do matrimônio, depois o reconhecimento da união estável.

A Carta Magna, de 1988, trouxe, em seu artigo 226, a proteção à família pelo Estado e o reconhecimento das várias espécies de famílias. Estas geralmente formadas pelo laço da afetividade, não importando apenas os princípios da hierarquização, patrimonialismo e individualismo promotores do matrimônio no passado. 
O Código Civil, de 2002, no direito de família, reconheceu a igualdade entre filhos e a união estável, bem assim, valorou as relações além do matrimônio, mantendo a monogamia. Entretanto, o foco sempre foi em resguardar o patrimônio familiar.

A partir daí, mudanças jurisprudenciais passaram a admitir o casamento entre pessoas do mesmo sexo e a adoção de crianças por casais homossexuais, mais recentemente possibilitaram a alteração no registro civil, com a inclusão do patronímio afetivo além do biológico, podendo o filho ter dupla paternidade, por meio do Provimento n ${ }^{\circ} 63$ do Conselho Nacional de Justiça, de 2017.

Diante disso, o presente estudo tem por objetivo geral analisar o papel do reconhecimento da filiação socioafetiva e da multiparentalidade no registro civil brasileiro à luz dos princípios que regem o direito de família. Já os objetivos específicos definidos foram: descrever a importância do arcabouço principiológico que rege o direito de família na atualidade; compreender o reconhecimento jurídico da diversidade fática dos arranjos familiares; e avaliar a regulação da multiparentalidade pelo Provimento n 63 do Conselho Nacional de Justiça, de 2017.

Com as alterações trazidas pela norma constitucional e as infraconstitucionais, os princípios da hierarquização, patrimonialismo e individualismo estão sendo quase que substituídos pelos princípios da afetividade, da solidariedade familiar, da proteção integral da criança e do adolescente, incluindo o melhor interesse da criança e do adolescente e da paternidade responsável, além de outros que não serão discutidos no presente estudo.

Entretanto, o princípio da afetividade é o precursor dos princípios mencionados acima, pois o afeto representa a interação e a ligação entre os indivíduos que convivem sobre o mesmo teto, com a intenção de gerar a família, o lar. Essa interação se dá pela subjetividade, com foco não só nos interesses patrimoniais, mas também nas relações de afınidade e de ligação afetiva entre os entes familiares.

Metodologicamente foi utilizada a abordagem qualitativa, que foi privilegiada, tendo em vista que o foco do nosso estudo não esteve centrado em aspectos quantitativos, mas sim na compreensão de uma realidade social, pautada nas relações humanas. Já o método de pesquisa adotado foi o dialético, o qual visa estudar o objeto de estudo em sua integralidade, observando seus pontos positivos e negativos. $\bigcirc$ estudo foi o bibliográfico, constituído por meio de amparo dos teóricos sobre o assunto abordado, realizado em livros, artigos científicos e trabalhos acadêmicos. Por fim, quanto à técnica de coleta de dados, foi utilizada a documental, realizada nos julgados e nos atos normativos, em particular no Provimento no 63 do Conselho Nacional de Justiça, de 2017.

Em um primeiro momento, foram abordados os princípios que regem o Direito de Família, descrevendo a importância que eles têm na atualidade; em seguida, comentou-se como tais princípios têm propiciado o reconhecimento jurídico da diversidade de arranjos familiares existentes na sociedade; por fim, focou-se no 
Provimento $\mathrm{n}^{\circ} 63$ do Conselho Nacional de Justiça, de 2017, avaliando como ele tem impactado as relações familiares.

\section{A IMPORTÂNCIA DO ARCABOUÇO PRINCIPIOLÓGICO QUE REGE O DIREITO FAMILIAR NO BRASIL}

Os princípios são fontes do direito de relevante utilidade para regulamentação das relações sociais, principalmente por serem a mola propulsora das normas de condutas, desde a Carta Máxima até os Regimentos e Regulamentos das relações jurídicas de um país. Cotidianamente, os princípios são reconhecidos como espécies de normas, assim como as regras. E os estudiosos que adotam essa tese se baseiam na teoria da ponderação e da adequabilidade, são eles: Josef Esser, Ronald Dworkin, Robert Alexy (PEREIRA, 20 I 5).

O direito de família brasileiro não foi nem é diferente; as normas regulamentadoras também foram baseadas em princípios. Entretanto, os princípios eram utilizados como regras supletivas às leis. Com o passar dos tempos, eles foram ganhando mais efetividade e, conforme afirma Valadares (2005, p. 3), "Com a evolução e desenvolvimento do direito civil-constitucional, os princípios ganharam uma nova força normativa. Eles deixaram seu caráter supletório para ocupar o lume e o centro da interpretação normativa". Essa interpretação foi primordial para evitar a aplicação pura da lei e também para afastar os julgamentos morais na aplicação das regras de condutas familiares. Ideia amparada na ponderação e adequação da melhor interpretação na aplicação das normas.

No direito familiar, inicialmente, os princípios basilares eram os da hierarquização, do patrimonialismo e do individualismo, conforme já mencionado.

O princípio do patrimonialismo se revela muito parecido com o patriarcado, no qual existe uma fonte do poder, e este poder é do marido, que se torna o senhorio da casa, por meio do matrimônio e muitas vezes por uniões formalizadas por interesses e alianças familiares. A mulher, esposa, está subordinada ao marido, seu senhor, por dependência econômico-financeira e emocional, e não tem voz. Muito se assemelha à escravidão. O marido/senhor dá as ordens domésticas, julga os conflitos e aplica o poder disciplinar. A esposa e os filhos apenas cumprem. Ele detém todo o poder de mando e do patrimônio, adquirido a partir da relação de patriarcado estabelecida, que o toma por senhor de todas as coisas e pessoas (AGUIAR, 2000).

O princípio da hierarquização, originário do patriarcado, estabelece o poder hierárquico e de mando ao marido. Pessoa que ninguém se sobrepõe, é a autoridade máxima do lar. $\bigcirc$ vínculo se dá pela afetividade muitas vezes com o casamento, mas privilegia a arbitrariedade ante o autoritarismo do pater familia (AGUIAR, 2000). 
princípio do individualismo representa a ideia de transmissão do patrimônio e a procriação, pouco importando o bem-estar familiar no aspecto da afetividade. Os filhos muitas vezes buscam distâncias de seu genitor, estabelecendo sua própria moradia, distante da opressão vivenciada desde seu nascimento. $\bigcirc$ que privilegia é o egocentrismo (SOUSA; WAQUIM, 20I5).

Esses princípios basilares do direito de família foram contemplados nas constituições anteriores à de 1988 e no Código Civil, de 1916. Entretanto, aos poucos eles começaram a ser questionados, principalmente com a mulher assumindo um papel de importância no contexto familiar. Tais mudanças ganharam força e foram sendo consolidadas com o ingresso da Carta Magna Cidadã, de 1988', a partir das realidades oriundas das mudanças sociais advindas dos diversos movimentos aclamadores pela igualdade entre os entes familiares e a mudança de comportamento da mulher, abandonando o papel de submissa para estar lado a lado com o marido/companheiro na administração doméstica.

Com isso, novos princípios passaram a ganhar relevância no Direito familiar, dos quais serão destacados, no presente estudo, os seguintes: princípio da dignidade da pessoa humana, princípio da afetividade, princípio da solidariedade familiar, princípio da proteção integral da criança e do adolescente (associado ao princípio do melhor interesse da criança) e o princípio da paternidade responsável. A seguir será estudado cada um desses princípios individualmente.

Inicia-se com o princípio da dignidade da pessoa humana, devido à sua relevância para os demais princípios no regramento do direito familiar, considerado como princípio máximo, possuindo caráter fundamental na Carta Magna, de 1988 , o qual promove uma despatrimonialização do Direito privado, abrindo espaço para o respeito à pessoa humana em detrimento ao aspecto patrimonial (TARTUCE, 2017). Esse princípio prioriza o "ser" no sentido de existência da pessoa ante qualquer juízo de valor de origem e preconceitos diversos (HINORAKA, 2000). Trata-se de um princípio que privilegia e promove a pessoa humana pela sua existência.

As lutas de classes e os movimentos sociais muito contribuíram para o rompimento daquele formato de família patriarcal, para uma família com mais democracia e divisão dos papeis igualitários, amparada não só no patrimônio, mas com a afetividade, por meio de um vínculo afetivo e interativo que ligava os membros no

I Antes da CF/88, podem ser citadas duas normas importantes na reformulação da família no Brasil, a primeira foi a o Estatuto da Mulher Casada (Lei 4.121/1962) que influenciou a promoção da "emancipação da mulher, que pôde tornar-se economicamente ativa sem necessitar da autorização do marido, passou a ter direito sobre os seus filhos e compartilhar do poder familiar, podendo pleitear a guarda em caso de separação" (SOUZA; BELEZA; ANDRADE, 20।2, p. 107). A outra foi Lei do Divórcio (Lei 6.5 I5/1977), a qual permitiu a dissolução do casamento, permitindo que as pessoas pudessem reconstruir suas vidas, quando não houvesse mais sentido a continuidade da relação conjugal. 
lar. $\bigcirc$ que era casa, com um senhor patriarcal, individual, passou a ser o lar, com o afeto nos laços que unia os parentes, não mais só pai, mãe e filhos(as), mas todos que formavam o vínculo familiar.

$\bigcirc$ princípio da afetividade tomou o espaço da rigidez que envolvia os entes da antiga entidade familiar. $\bigcirc$ casamento passou a ser formado por pessoas que se amam, e quando o amor acaba não há necessidade de viver obrigado com o outro, e a tristeza, a raiva e muitos sentimentos negativos passam a mover a relação. Afeto não é amor, é muito mais. É compreensão (VALADARES, 2005). Há uma ruptura do velho discurso jurídico de família (PEREIRA, 20 I 5).

"O sujeito de direito é também um sujeito de desejo. Isso muda tudo. As muIheres se veem, então, como sujeitos na relação conjugal e parental, e não mais como assujeitadas ao pai ou ao marido" (PEREIRA, 20 I5, p. 3). Elas deixam de ser objeto do lar, para serem entes do lar com direitos e obrigações, não apenas patrimonial, mas também de afeto e desejo. Não são mais obrigadas a manter o vínculo conjugal por obrigação, mas por prazer. "Quebra-se, assim, uma resignação histórica das mulheres que sustentavam os casamentos" (PEREIRA, 20I 5, p. 3). $\bigcirc$ princípio da afetividade questiona a prevalência do patriarcado, priorizando o afeto, a compreensão e o desejo de estar no mesmo espaço doméstico aos entes familiares.

O princípio da solidariedade familiar, nas palavras de Lisboa (2002, p. 46): "são vetores que indicam o dever de cooperação mútua entre os membros da família e entre os parentes, para fins de assistência imaterial (afeto) e material (alimentos, educação, lazer)". Isso quer dizer que há a necessidade de colaboração de todos os entes que formam a família em todos os aspectos. Primordialmente o afeto, a compreensão, o auxílio mútuo, para daí haver a divisão econômico-financeira. As pessoas se respeitam e respeitam as liberdades individuais.

Há o desejo de estar no mesmo espaço doméstico, por tudo que é praticado, distribuído e estabelecido democraticamente entre os conviventes. Esposas e filhos têm os mesmos direitos, deveres e desejos que os pais. Estes últimos não ditam as regras. As famílias não são apenas com a presença de um pai, uma mãe e os filhos. Existem vários laços afetivos envolvidos dos mais diversos membros que formam a relação familiar. Há uma diversidade de espécies de famílias, de acordo com a afetividade que une os entes envolvidos na relação.

Daí surge outro princípio, o da proteção integral da criança e do adolescente, e este inclui o princípio do melhor interesse da criança e do adolescente. Estes princípios se complementam, pois, no dizer de Santos (2006, p. 130),

A doutrina da proteção integral da criança e do adolescente afırma o valor intrínseco como ser humano; a necessidade de especial respeito à sua condição de pessoa em desenvolvimento; o valor prospectivo da infância e da juventude, como portadora da continuidade de seu povo e da espécie e o reconhecimento da sua 
vulnerabilidade o que torna as crianças e os adolescentes merecedores de proteção integral por parte da família, da sociedade e do Estado, o qual deverá atuar através de políticas específicas para promoção e defesa de seus direitos.

princípio da proteção integral prima pelo respeito à criança e ao adolescente, por ser um indivíduo em formação biológica, física e psíquica, daí a necessidade de cuidados e atenção especiais, para o bom desenvolvimento desses seres até a vida adulta, chegando à maturidade apoiados no bem-estar e na plenitude de seus direitos. Desse modo, tanto a família quanto o Estado são responsáveis pela formação e desenvolvimento dessas pessoas. Proteção tem o sentido de minorar ou evitar riscos à dignidade da criança e do adolescente.

A criança e o adolescente são vulneráveis porque estão expostos às mais diversas ações dos adultos e desprovidos de maturidade, compreensão para tomar decisões ou se libertarem de riscos, violências e principalmente de se manterem vivos sem o apoio, a proteção, o cuidado de alguém que saiba defendê-los de todas as intempéries da vida.

Quanto ao princípio do melhor interesse da criança e do adolescente, nas palavras de Diniz (2010), este garante o pleno desenvolvimento da personalidade desses sujeitos e serve como parâmetro para dirimir conflitos das relações familiares, como divórcio, guarda, direito de visita etc.

Sendo assim, os filhos, as crianças ou os adolescentes, no seio da família, devem ser respeitados, e não igualados a objetos de desejos de seus genitores. Muito menos serem utilizados como objetos de vingança pelo desfazimento da vida conjugal dos pais. Daí a possibilidade da destituição do poder familiar, nos mais diversos casos de violências contra eles.

E por fim o princípio da paternidade responsável, o qual, de acordo com a Constituição Federal, de 1988, em seu art. 226, parágrafo $7^{\circ}$, estabelece que:

Art. 226. A família, base da sociedade, tem especial proteção do estado:

$[\ldots]$

$\S 7^{\circ}$. Fundado nos princípios da dignidade da pessoa humana e da paternidade responsável, o planejamento familiar é livre decisão do casal, competindo ao Estado propiciar recursos educacionais e cientíícos para o exercício desse direito, vedada qualquer forma coercitiva por parte de instituições oficiais ou privadas.

Compreende-se, a partir do artigo em comento, que a paternidade responsável inibe a intervenção do Estado no planejamento familiar. A idealização da família é de livre e espontânea vontade do casal. Cabe apenas ao Estado buscar propiciar e garantir condições de saúde, educação, moradia, alimentação, enfim, sobrevivência aos genitores para a realização desses direitos. 
A responsabilização dos pais pela gestação, nascimento e cuidado com os fiIhos é direta, ou seja, independe de ação de outrem para aplicação de uma sanção pelos maus-tratos, negligência e imprudência no cuidado com sua prole.

Assim, aduz Pires (200I, online): "um planejamento familiar racional e independente, para que os seus membros possam se desenvolver naturalmente". Isso quer dizer que o planejamento familiar é trazer o filho ao mundo com responsabilidade e desejo de tê-lo, para que, ao nascer, o bebê, depois criança, e em seguida adolescente, possa desenvolver-se normalmente, sem problemas físicos, psíquicos, biológicos, entre outros, por conta de maus-tratos, de abandono, de desrespeito e, pior, do não desejo de sua existência.

A paternidade responsável corresponde ao dever de proteção integral e garantia de uma vida saudável à criança e ao adolescente, pelo fato de sua existência, que representa o respeito à dignidade da pessoa humana, amparada pelo afeto, desejo e prazer pela sua vida no seio familiar, nas mais diversas espécies de famílias existentes na atualidade.

\section{O RECONHECIMENTO JURÍDICO DA DIVERSIDADE FÁTICA DOS ARRANJOS FAMILIARES}

A substituição do modelo familiar patriarcal e matrimonial, pautado na hierarquização, no patrimonialismo e no individualismo pelo entendimento principiológico das relações familiares, surgiu a partir de mudanças sociais importantes que redefiniram os papéis das pessoas que formam uma família.

Conforme Dias (2004), a sociedade moderna, marcada pela globalização, permitiu o rompimento de três paradigmas que condicionavam a família que eram: o casamento, o sexo e a reprodução, pois o advento da emancipação feminina, a evolução dos costumes e o desenvolvimento dos estudos voltados para a engenharia genética possibilitaram que o casamento deixasse de ser indispensável para o reconhecimento do núcleo familiar. Além disso, houve a ampliação da liberdade sexual, tornando antiquada a ideia de que o sexo deva ser praticado exclusivamente no âmbito matrimonial e com fins meramente procriacionais.

O debate feminista permitiu uma ampliação dos direitos das mulheres e uma participação delas na sociedade, o que repercutiu decisivamente nas famílias, porque as mulheres deixaram os espaços eminentemente privados e o exercício exclusivo do cuidado com a casa e a criação dos filhos, para ingressarem no mercado 
de trabalho, gerando a diminuição da prole, a reprodução tardia (ou até mesmo a opção pela não geração de filhos), o compartilhamento das tarefas domésticas².

Além disso, outros fatores foram decisivos para mudanças na formação tradicional da família, como o divórcio e o reconhecimento dos filhos como sujeitos de direitos, com base na doutrina da proteção integral das crianças e dos adolescentes, inaugurada no ordenamento jurídico brasileiro pela Constituição Federal, de 1988, e ratificada e ampliada pelo Estatuto da Criança e do Adolescente (Lei $n^{\circ} 8.072$, de 1990).

Lima (20|4, p.25) sintetiza as mudanças sociais que influenciaram o formato das famílias na atualidade, afirmando que na Idade Contemporânea

[...] houve a formação dos grandes centros urbanos, a revolução sexual, o movimento feminista, que puseram em cheque padrões morais, a disseminação do divórcio e, finalmente, a reformulação do conceito de família que passou a admitir os mais variados arranjos, acompanhando a evolução da humanidade.

Diante disso, e considerando que o antigo Código Civil, de 1916, apenas reconhecia como entidade familiar aquela formada pelo casamento, como também diferenciava os filhos em "legítimos" e "ilegítimos", sendo estes últimos havidos fora da relação conjugal, era necessário que o direito civilista brasileiro pudesse se ajustar à realidade fática moderna, reconhecendo os mais diversos formatos familiares já existentes ${ }^{3}$.

Nesse sentido, a Constituição Federal, de 1988, foi bastante importante, pois a partir dela houve uma ampliação do reconhecimento da entidade familiar, passando a ser considerada como tal as instituições familiares formadas a partir da União Estável, bem como os casos de famílias monoparentais, dotadas pela presença do pai ou da mãe com filhos, além das anaparentais, que se caracterizam pela ausência da figura paterna, formadas pelos vínculos colaterais.

2 É preciso ressaltar que apesar dos avanços nos direitos das mulheres, o patriarcado não foi totalmente superado (e ainda está muito longe de o ser) das relações familiares, em muitos casos as mulheres acumulam exaustivamente as atribuições produtivas no mercado de trabalho, com as reprodutivas, no seio domiciliar, gerando o que Ávila (2009) denomina de jornada intermitente.

3 Conforme Souza e Dias (2000), por muito tempo, a legislação permaneceu omissa para o reconhecimento de outras relações familiares, além de impedir efeitos jurídicos de qualquer outro vínculo afetivo, que não fosse o casamento, contudo, na prática os relacionamentos ocorriam, levando os envolvidos a procurar o judiciário para dirimir conflitos decorrentes dessas relações, obrigando o judiciário a criar meios alternativos para resolução desses casos. Inicialmente, era aplicado analogamente o Direito Comercial, sendo a relação dos conviventes equiparada a uma sociedade de fato, nas hipóteses em que não havia patrimônio destinado a partilha, equiparava-se a relação a uma laboral, a partir do pagamento de indenização pelos serviços prestados. 
Ademais, nossa Carta Magna dirime a diferenciação entre os filhos, sejam eles biológicos, adotivos, havidos, ou não, no casamento, todos são considerados iguais, até mesmo para os fins sucessórios e patrimoniais. Neste momento, conforme já foi visto neste estudo, o direito de família é amparado no arcabouço principiológico; podemos também aduzir que a entidade familiar está intimamente ligada à afetividade. Souza, Beleza e Andrade (20 I2, p. I I0) destacam

As inúmeras mudanças e transformações dos séculos $X X$ e $X X \mid$ produziram reflexos nas relações familiares, intensificando novos e variados arranjos familiares, bem como as concepções de conjugalidade e parentalidade. Na contemporaneidade, o que vai identificar a família já não é mais a celebração do casamento ou do envolvimento de caráter sexual e sim o afeto que permeia o relacionamento. A afetividade será o principal sentimento a sustentar a formação dos relacionamentos conjugais.

A família continua sendo identificada como lócus de primeira socialização do indivíduo, como uma importância sine qua non para formação da personalidade de cada pessoa, uma família estruturada continua sendo fundamental para definir quem aquela pessoa será no futuro. Entretanto, atualmente a compreensão do que seria uma "família estruturada" está baseada na afetividade entre os componentes familiares, e não na obrigatoriedade da presença do padrão tradicional, formado pela presença de pai, mãe e filhos.

Convém advertir que o estudo sobre as famílias deve ser amparado na "desconstrução de nossos conceitos prontos, buscando o desprendimento dos preconceitos para podermos entender as novas configurações familiares" (OLIVEIRA, 2009, p. 84).

É preciso destacar, entretanto, que da Promulgação da Carta, de 1988, novas mudanças nas relações sociais propiciaram a criação de novos arranjos familiares, que vão além do casamento, da união estável e da família monoparental, reconhecidas pelos constituintes. Lôbo (2002) defende que é preciso compreender as famílias para além do numerus clausus descrito na Constituição; para ele, as entidades familiares caracterizam-se pela presença dos seguintes elementos: afetividade, estabilidade e ostensibilidade. $O$ mesmo autor, em seu livro de doutrina sobre o Direito de Família chegou a enumerar onze formações familiares, que são reconhecidas direta ou indiretamente pelo direito brasileiro, são elas: 
a) homem e mulher, com vínculo de casamento, com filhos biológicos;

b) homem e mulher, com vínculo de casamento com filhos biológicos e não biológicos, ou somente com filhos não biológicos;

c) homem e mulher, sem casamento, com filhos biológicos (união estável);

d) homem e mulher, sem casamento, com filhos biológicos ou apenas não biológicos (união estável);

e) pai ou mãe e filhos biológicos (entidade monoparental);

f) pai ou mãe e filhos biológicos e adotivos ou apenas adotivos (entidade monoparental);

g) união de parentes e pessoas que convivem em interdependência afetiva, sem pai ou mãe que a chefie, como no caso de grupo de irmãos, após falecimento ou abandono dos pais, ou de avós e netos, ou de tios e sobrinhos;

h) pessoas sem laços de parentesco que passam a conviver em caráter permanente, com laços de afetividade e de ajuda mútua, sem finalidade sexual ou econômica;

i) uniões homossexuais, de caráter afetivo e sexual;

j) uniões concubinárias, quando houver impedimento para casar de um ou de ambos companheiros com ou sem filhos;

l) comunidade afetiva formado com "filhos de criação", segundo generosa e solidária tradição brasileira, sem laços de filiação natural ou adotiva regular, incluindo nas famílias recompostas, as relações constituídas entre padrastos e madrastas e respectivos enteados, quando se realizem os requisitos da posse de estado de filiação (LÔBO, 20। 0, p.73).

Este rol descrito pelo doutrinador, contudo, não esgota as possibilidades de arranjos familiares, as relações sociais são dinâmicas e aos poucos o direito vem reconhecendo outros tipos de arranjos, como nos casos de multiparentalidade, que serão abordados no próximo tópico.

\section{A REGULAÇÃO DA MULTIPARENTALIDADE PELO PROVIMEN- TO NN 63 DO CONSELHO NACIONAL DE JUSTIÇA}

Conforme descrito anteriormente, os novos arranjos familiares repercutiram no direito de família. Tal repercussão permitiu a alteração do foco do plano da legitimidade para o da afetividade, a partir disso foi redirecionada a função tradicionalmente reconhecida da presunção pater is est:

Destarte, sua função deixa de ser a de presumir a legitimidade do filho, em razão da origem matrimonial, para a de presumir a paternidade em razão do estado de filiação, independentemente de sua origem ou de sua concepção. A presunção da concep- 
ção relaciona-se ao nascimento devendo este prevalecer ( $\mathrm{LOBO}$, 2004, p.28).

Ou seja, a presunção de paternidade concretiza-se a partir da observância da relação do estado de filiação. Aduz Lobo (2004) que o estado de filiação é constituído quando uma pessoa assume o papel de filho, perante outra(s) pessoa(s) que assume $(m)$ o papel de pai ou mãe, podendo haver, ou não, entre elas vínculo biológico.

Tal autor afirma ainda que o estado de filiação possa ser conceituado como uma qualificação jurídica do vínculo de parentesco, atribuída às pessoas que integram essa relação "compreendendo um complexo de direitos e deveres reciprocamente considerados. $O$ filho é titular do estado de filiação, da mesma forma que o pai e a mãe são titulares dos estados de paternidade e de maternidade em relação a ele" (LOBO, 2004, p. 2I).

É mister diferenciar o estado de filiação do direito ao conhecimento da origem genética, o primeiro, como foi visto, está associado à assunção recíproca dos papéis de filho e de pai ou mãe, gerando uma série de efeitos jurídicos; o segundo, por sua vez, está relacionado ao conhecimento do indivíduo de sua filiação biológica, a fim de que possa conhecer suas origens, sua herança genética. Convém destacar que "a existência de filiação socioafetiva registral não obsta a investigação da filiação biológica, justamente por esse ser um direito personalíssimo, indisponível e imprescritível" (ARTONI, 20 I9, p. 47).

O estado de filiação não pode ser confundido com a filiação biológica, é plenamente possível que ele possa ser constituído mediante a afetividade desenvolvida entre determinadas pessoas, construindo uma relação de pai-filho/pai-filha/mãe-fiIho/mãe-filha. Nessas hipóteses, ficará configurada a filiação socioafetiva.

O estado de filiação, entretanto, por muito tempo, esteve restrito ao modelo dual de parentalidade, o qual "exigia que o indivíduo fosse registrado por um homem e uma mulher, ou seja, sempre duas pessoas, mas de sexos distintos. Esse modelo dúplice sofreu uma primeira modificação com a adoção de pessoas por casais homossexuais" (CASSETTARI, 20 I 5, p. 157).

Dessa forma, alguns dos primeiros casos de reconhecimento de dupla paternidade ou maternidade estavam associados à adoção homoafetiva; contudo, a multiparentalidade envolve outras hipóteses de formações familiares. $\bigcirc$ quadro a seguir conceitua alguns modelos parentais, diversos do padrão dual: 
O RECONHECIMENTO DA FILIAÇÃO SOCIOAFETIVA E DA MULTIPARENTALIDADE NO REGISTRO CIVIL BRASILEIRO À LUZ DOS PRINCÍPIOS QUE REGEM O DIREITO DE FAMÍLIA

\begin{tabular}{|l|l|}
\hline \multicolumn{1}{|c|}{ Nomenclatura } & \multicolumn{1}{c|}{ Conceito } \\
\hline $\begin{array}{l}\text { MULTIPARENTALIDADE } \\
\text { PATERNA }\end{array}$ & $\begin{array}{l}\text { 3 ou mais pessoas como genitores, com dois ou mais pais } \\
\text { do sexo masculino }\end{array}$ \\
\hline $\begin{array}{l}\text { MULTIPARENTALIDADE } \\
\text { MATERNA }\end{array}$ & $\begin{array}{l}\text { 3 ou mais pessoas como genitores, com duas ou mais mães } \\
\text { do sexo feminino }\end{array}$ \\
\hline BIPARENTALIDADE & 1 pai e 1 mãe de sexos distintos \\
\hline $\begin{array}{l}\text { BIPATERNIDADE } \\
\text { (ou Biparentalidade Paterna) }\end{array}$ & 2 pais do sexo masculino apenas \\
\hline $\begin{array}{l}\text { BIMATERNIDADE } \\
\text { (ou Biparentalidade Materna) }\end{array}$ & 2 mães do sexo feminino apenas \\
\hline
\end{tabular}

Fonte: CASSETTARI, 2015, p. 160.

Neste estudo, será dado foco aos casos de multiparentalidade, seja ela paterna ou materna. Cassettari (20 I5) realizou um levantamento bastante interessante e completo sobre a multiparentalidade nos julgados de diversos tribunais brasileiros. Conforme o autor, como o tema é polêmico, inicialmente era considerado impossível que uma pessoa pudesse ter múltipla parentalidade, ele cita a Apelação Cível 70027 I I 2 I 92 da Oitava Câmara Cível do Tribunal de Justiça do Rio Grande do Sul, sob a relatoria do desembargador Claudir Fidélis Faccenda (2009).

No caso, o autor alegava a existência de paternidade sociafetiva; contudo, não a desejava sem anulação da paternidade registral do pai. À época, tal pedido foi considerado juridicamente impossível, tendo em vista que o entendimento era o de que ninguém poderia ser filho de dois pais. $\bigcirc$ direito, entretanto, não poderia ficar alheio à dinamicidade fática das relações familiares, sendo levados inúmeros casos à apreciação judicial, em que o debate estava centrado na possibilidade de uma pessoa ter mais de um pai ou de uma mãe.

Cassettari (2015) apresenta ainda outros julgados de reconhecimento de paternidade/maternidade socioafetiva, como: (i) a Apelação Cível nº00642226.20 I I.8.26.0286, julgada pelo Tribunal de Justiça do Estado de São Paulo (20 I I); (ii) a sentença em primeira instância da primeira Vara Cível da Comarca de Ariquemes, localizada em Rondônia, relativa aos Autos do Processo n 0012530 95.2010.8.22.0002; (iii) a sentença de primeira instância da Vara da Infância e Juventude na Comarca de Cascavel, no Paraná, referente aos Autos do Processo n 0038958-54.2012.8.16.0021, entre outros.

Os casos envolvem diversas possibilidades de formações familiares, em que a multiparentalidade tornou-se efetiva devido às relações de madastrio/padastrio ou de adoção, como também casos de adoção à brasileira, além dos casos de morte de um dos genitores ou reconhecimento de paternidade biológica posterior. Em todos esses casos observa-se uma tendência para o reconhecimento da paternida- 
de socioafetiva, o que ensejou a máxima "a parentalidade afetiva prevalece sobre a biológica", consagrada na jurisprudência.

Artoni (2019) traz à tona a mesma percepção, com base em seus estudos sobre "filiação sociafetiva" nos julgados do Superior Tribunal de Justiça (STJ), no período de 2007 até 2019.

A autora constata uma tendência pelo privilégio da socioafetividade, apesar de elencar casos excepcionais em que prevaleceu a filiação biológica. $\bigcirc$ grande imbróglio, entretanto, estava no questionamento sobre qual das parentalidades (a socioafetiva ou a biológica) deveria ser consignada no registro de nascimento, considerando todos os efeitos cíveis decorrentes dessa consignação.

O debate foi consolidado, em agosto de 2016, por meio da Decisão do Supremo Tribunal Federal (STF) no Recurso Extraordinário nº 898.060/SC, sob a relatoria do ministro Luiz Fux, em que foi adotada a tese $n^{\circ} 622$ : "A paternidade socioafetiva, declarada ou não em registro público, não impede o reconhecimento do vínculo de filiação concomitante baseado na origem biológica, com todas as suas consequências patrimoniais e extrapatrimoniais". O caso obteve repercussão geral, passando tal tese a ser adotada em situações semelhantes, legitimando a possibilidade da presença de mais um pai ou uma mãe nos assentos registrais de uma pessoa. É possível afirmar que:

A decisão do STF foi inovadora ao redefinir os contornos da filiação, reconhecendo juridicamente a afetividade, a isonomia jurídica entre as filiações socioafetiva e biológica, não sendo possível afirmar, a priori, que uma modalidade de vínculo deva prevalecer em detrimento da outra, e acolheu a possibilidade da multiparentalidade, configurando um avanço no direito das famílias (FRANCO; EHRHARDT JÚNIOR, 2018, p, 23I).

A decisão do Supremo Tribunal Federal possibilitou a existência da multiparentalidade, mas a ausência de regulamentação sobre o tema prejudicava o exercício pleno do direito das pessoas inseridas em formações familiares desse tipo. Visando suprir essa lacuna, o Conselho Nacional de Justiça (CNJ) editou o Provimento ${ }^{\circ}$ 63, em novembro de 2017, regulamentando o reconhecimento da paternidade socioafetiva.

Tal provimento é extenso e versa sobre a paternidade socioafetiva, em sua segunda seção, nos artigos 10 a I 5 . $O$ texto define que o reconhecimento da paternidade (e da maternidade) socioafetiva será voluntário e extrajudicial, e efetivado espontaneamente pelo interessado, diretamente perante os oficiais de registro civil das pessoas naturais. Além disso, atendendo à recomendação do Instituto Brasileiro de Direito de Família (IBDFam), foi regularizada a multiparentalidade, permitindo o registro de até dois pais e/ou duas mães no campo "filiação" no assento de nascimento. 
Observa-se, portanto, que o Provimento $n^{\circ} 63$ do Conselho Nacional de Justiça, de 2017 , tem sido fundamental para consolidação do reconhecimento jurídico das formações familiares pluriparentais, estando alinhado com os princípios do direito de família.

Compreende-se que as famílias caracterizadas pela multiparentalidade, que outrora não eram reconhecidas pelo Direito, não tinham respeitado plenamente o princípio da dignidade da pessoa humana, porque os arranjos familiares em que viviam eram marginalizados juridicamente, havendo até mesmo prejuízos decorrentes dos aspectos sucessórios e alimentares causados por essa ausência de reconhecimento.

"O princípio constitucional da dignidade da pessoa humana tem um conteúdo que excede os direitos fundamentais enumerados na Constituição" (SARMENTO, 2016 , p. 308); desse modo, faz-se necessário que todos possam tê-la respeitada em sua individualidade, e ter sua formação familiar reconhecida juridicamente, sem haver discriminações pelo fato de o indivíduo não estar enquadrado numa família considerada como "tradicional".

Até mesmo o uso do sobrenome da família socioafetiva é importante, uma vez que permite o direito à identidade pessoal do indivíduo. Destaca-se que o nome como um todo é reconhecido pela doutrina como um dos direitos de personalidade, já que ele "é o signo linguístico que identifica a pessoa no meio social" (VIEIRA, 2009 apud VECCHIAATTI, 20 I 5). Sabe-se que

O não ingresso da filiação socioafetiva nos registros públicos marginaliza os indivíduos que vivem a socioafetividade, dificultando-lhes o exercício dos direitos e deveres inerentes à filiação, como, por exemplo, guarda e tutela, alimentos, visitas, direitos inerentes ao parentesco, hereditários, direito ao nome, entre muitos outros (ARTONI, 2019, p. 45).

Portanto, a inserção paternidade socioafetiva, mesmo nos casos de multiparentalidade nos assentos registrais, coaduna-se com a maior observância do princípio da dignidade da pessoa humana.

De outro modo, pode-se inferir que o status quo anterior à vigência do Provimento $n^{\circ} 63$ do Conselho Nacional de Justiça, de 2017, não permitia plena observância do princípio da afetividade e da solidariedade familiar, tendo em vista que havia uma orientação jurisprudencial para escolha de apenas um pai ou uma mãe para figurar no assento registral, quando na realidade fática inúmeras famílias conviviam e reconheciam socialmente a presença de mais uma parentalidade, expressa no polo materno e/ou paterno. Nesse sentido, é interessante a reflexão:

(...) de que não há gesto mais belo do que buscar a declaração da parentalidade de um filho afetivo, com quem não possui laços biológicos, com todas as consequências jurídicas que a parenta- 
lidade sanguínea irá ensejar nesse caso, trazendo uma série de deveres para a pessoa que pretende tal pedido (CASSETTARI, 2015, p. 178).

Esta declaração expressa com clareza os princípios da afetividade e da solidariedade familiar, sendo, portanto, justo o reconhecimento jurídico dessa relação familiar. Pode-se dizer também que o ato Normativo do Conselho Nacional de Justiça permitiu um melhor atendimento ao princípio da proteção integral da criança e do adolescente (associado ao princípio do melhor interesse da criança), bem como ao princípio da paternidade responsável, pois permitirá que essa criança e/ ou adolescente que possua dois pais ou duas mães tenha uma ampliação dos seus direitos, como também possa conformar seu assento de nascimento com a realidade fática em que está inserida.

É bem verdade, contudo, que a multiparentalidade e o Provimento $n^{\circ} 63$ do Conselho Nacional de Justiça, de 2017, também têm sido alvos de críticas por parte de alguns juristas. Podemos citar o voto vencido do ministro Dias Toffoli, no Recurso Extraordinário n 898.060/SC. De fato, o referido voto é anterior ao Provimento em comento; contudo, ele merece ser destacado pela crítica que o referido ministro tece a respeito da multiparentalidade.

Segundo Toffoli ${ }^{4}$, receia-se que haja confusão entre "o vínculo familiar com o vínculo registral que define as relações de parentesco sob o enfoque jurídico"; para o ministro, é preciso diferenciar a paternidade socioafetiva, que deve estar adstrita aos casos de adoção, com as situações de cuidado, decorrentes da guarda ou da tutela. Além disso, ele adverte que a tese sobre o tema "há de ser minimalista, diante da peculiaridade do caso concreto e para não abrirmos espaço para um debate, que no nosso pensar, deve ser realizado pelos legisladores". A preocupação do ministro é legítima; contudo, deve ser considerado que ela:

[...] tem como outra face a subestimação à verdade real dos que efetiva e conscientemente vivenciam vínculo filiativo de forma exclusivamente afetiva. Não é justo que o receio de que parte da sociedade faça uso impróprio e vulgar do instituto da filiação socioafetiva acabe por penalizar e marginalizar sujeitos que efetivamente vivenciem a filiação socioafetiva de forma consciente e séria (ARTONI, 2019, p.53).

A respeito do Provimento $n^{\circ} 63$ do Conselho Nacional de Justiça, de 2017 especificamente, a mesma autora aponta algumas lacunas que o ato normativo possui, a saber:

4 TOFFOLI, Dias. Voto vogal, proferido no julgamento do REXT n. 898.060/SC. Disponível em: <http://www.stf.jus.br/arquivo/cms/noticiaNoticiaStf/anexo/RE898060DT.pdf>. Acesso em: 3 ago. 2019 . 
i) a não participação do Ministério Público no procedimento extrajudicial de reconhecimento de filiação socioafetiva; ii) a potencialidade de utilização distorcida deste Provimento, para driblar o tradicional procedimento de adoção; e, iii) a espécie normativa eleita para a regulamentação da filiação socioafetiva ${ }^{5}$.

É preciso, portanto, que haja maiores debates doutrinários sobre o Provimento $n^{\circ} 63$ do Conselho Nacional de Justiça, de 2017, os quais possam aparar arestas que prejudicam sua melhor aplicabilidade no ordenamento jurídico; apesar disso, tal provimento mostra-se um tanto relevante, por permitir que haja o reconhecimento jurídico das famílias multiparentais, respeitando o arcabouço principiológico do direito de família.

\section{CONSIDERAÇÕES FINAIS}

O presente estudo teve por objetivo analisar o papel do reconhecimento da filiação socioafetiva e da multiparentalidade no registro civil brasileiro à luz dos princípios que regem o direito de família.

Inicialmente, foi realizada uma descrição dos princípios que regem o direito familiar, sendo destacado o princípio da dignidade da pessoa humana, como também o princípio da afetividade e o da solidariedade familiar, que versam sobre um novo paradigma de caracterização do modelo familiar nos dias atuais, pautado no afeto e no respeito entre os integrantes que compõem a família. Além disso, foram descritos o princípio da proteção integral da criança e do adolescente, que está intimamente relacionado ao princípio do melhor interesse da criança, e o princípio da paternidade responsável.

Posteriormente, buscou-se compreender a importância do reconhecimento jurídico da diversidade fática dos novos arranjos familiares. Foi visto que as mudanças sociais decorrentes da emancipação feminina e do descobrimento de novas tecnologias propiciaram o desenvolvimento de novos costumes, permitindo que aos poucos outras formações familiares, diversas às do modelo família tradicional (constituído unicamente pelo matrimônio de pessoas do sexo oposto), fossem sendo formadas, sem haver, contudo, regulação por parte do Direito, das relações entre essas pessoas, o que somente começou a mudar de forma mais incisiva, após a Constituição federal, de 1988, com a adoção de outras normas e o desenvolvimento da jurisprudência amparado nessa nova forma de visão do direito de família, cuja principal diretriz passou a ser a afetividade. Desse modo, o princípio da afetividade vem sendo a base para formação familiar.

5 A autora aponta que há debate sobre a competência do CNJ para regulamentar o tema por meio de provimento, parte da doutrina defende que tal matéria deveria ser regulada por lei. Vale recordar este posicionado está alinhado com o voto vencido do ministro Dias Toffoli no REXT n. 898.060/SC, já comentado neste trabalho. 
Mais adiante, foi abordado o conceito de paternidade socioafetiva, sendo dado enfoque ao objeto central do estudo, qual seja, a multiparentalidade. Em particular, foi analisado o Provimento n 63 do Conselho Nacional de Justiça, de 20 I7, que possibilitou o registro de até dois pais e duas mães no campo de filiação do assento registral.

A partir daí, foi possível analisar como o reconhecimento da filiação socioafetiva e da multiparentalidade nos assentos registrais de nascimento, propiciados pelo referido provimento, tem permitido um maior alinhamento do direito de família com seu arcabouço principiológico.

A aplicabilidade do princípio da dignidade da pessoa humana mostrou-se condizente com o dito ato normativo, por possibilitar que famílias, anteriormente estigmatizadas por estarem fora do "padrão" socialmente aceito, pudessem ter reconhecida sua unidade familiar. Ademais, garantiu as repercussões jurídicas desse reconhecimento, como os direitos sucessórios, alimentares, do uso do nome (garantido o direito à identidade pessoal) etc.

Da mesma forma, foi perceptível o alinhamento do Provimento no 63 do Conselho Nacional de Justiça, de 2017, com os princípios da afetividade e solidariedade familiar, pois a partir deste ato foi possível superar o entendimento jurisprudencial que optava por apenas um genitor para figurar no registro público, quando, a bem da verdade, havia famílias que possuíam mais de um pai ou mãe que exerciam o papel parental na relação de estado de filiação.

No que tange ao princípio da proteção integral da criança e do adolescente, o qual se relaciona diretamente ao princípio do melhor interesse da criança, e também ao princípio da paternidade responsável, mais uma vez observou-se alinhamento entre tais princípios e o dispositivo administrativo do Conselho Nacional de Justiça, uma vez que, a partir do Provimento, foi possível garantir as decorrências jurídicas do estado de filiação, protegendo e amparando a criança e ao adolescente, ao mesmo tempo reconhecendo a importância da responsabilidade parental.

Tal Provimento apresenta aspectos lacunosos; em particular, foi ressaltada, com base na doutrina, a ausência do Ministério Público durante o procedimento extrajudicial de reconhecimento de filiação socioafetiva; além da possibilidade de utilização do provimento para driblar o processo tradicional de adoção, principalmente nos casos de reconhecimento de filiação socioafetiva de crianças com pouca idade; por fim, o fato de o tema ser tratado pela via administrativa, quando deveria ser matéria legislativa.

Apesar disso, tal provimento pode ser considerado um marco para o direito "das" famílias brasileiras, uma vez que possibilitou a regularização e o reconhecimento de situações fáticas de arranjos familiares diversos, com base no afeto. 


\section{REFERÊNCIAS}

AGUIAR, Neuma. Patriarcado, sociedade e patrimonialismo. Scielo. Soc. estado. v. 15 no.2 Brasília June/Dec. 2000.Disponível em: <http://www.scielo.br/pdf/ se/vI5n2/vI5n2a06.pdf>. Acesso em: 29 jul. 2019.

ARTONI, Paula Baraldi. O registro civil da filiação socioafetiva no Direito brasileiro. Dissertação, Mestrado em Direito, Universidade Estadual Paulista "Júlio de Mesquita Filho", 2019.

ÁVILA, Maria Betânia de Melo. O tempo do trabalho das empregadas domésticas: tensões entre dominação/exploração e resistência. Tese, Doutorado em Sociologia. Recife: UFPE, 2009.

BRASIL. Constituição da República Federativa do Brasil de 1988. Disponível em: <http://www.planalto.gov.br/ccivil_03/constituicao/constituicao.htm> Acesso em: 31 jul. 2019

CASSETTARI, Christiano. Multiparentalidade e parentalidade socioafetiva: efeitos jurídicos. 2. ed. São Paulo: Atlas, 2015.

DIAS, Maria Berenice. Sociedade de afeto: um nome para a Família. Revista Brasileira de Direito Civil - RBDCivil | Belo Horizonte, v. 5, n. 5, p. 32-37, fev./ mar. 2004.

DINIZ, Maria Helena. Curso de direito civil brasileiro. v. 5: direito de família. 25 ed. São Paulo: Saraiva, 2010.

FRANCO, Karina Barbosa; EHRHARDT JÚNIOR, Marcos. Reconhecimento extrajudicialda filiação socioafetiva e multiparentalidade: comentários ao Provimento $n^{\circ}$ 63, de 14.1 1.17, do CNJ. Revista Brasileira de Direito Civil - RBDCivil | Belo Horizonte, v. 17, p. 223-237, jul./set. 2018.

HINORAKA, Giselda Maria Fernandes Novaes. Dos filhos havidos fora do casamento. 2000. Disponível em: <http://jus2.uol.com.br/doutrina/texto.asp?id=528. Acesso em: 30 jul. 2019.

LIMA, Ana Cecília de Araújo. Origem e evolução do Direito de Família. CAMPOS, Alyson Rodrigues Correia; LOBO, Fabíola Albuquerque; LEAL, Larissa Maria de Moraes (org.). Direito de família e sucessões. Editora Nossa Livraria, Recife: 2014. 
LÔBO, Paulo. Direito Civil: Famílias. 3. ed. São Paulo: Saraiva, 2010.

. Entidades familiares constitucionalizadas: para além do numerusclausus. Revista Brasileira de Direito Civil - RBDCivil | Belo Horizonte, v. 3, n. I2, p. 40-55, jan./mar. 2002.

. Direito ao estado de filiação e direito à origem genética: uma distinção necessária. Revista jurídica: órgão nacional de doutrina, jurisprudência, legislação e crítica judiciária. Ano 52, n. 316, p. 19-36, fev.2004.

OLIVEIRA, Nayara Hakime Dutra. Recomeçar: família, filhos e desafios [online]. São Paulo: Editora UNESP; São Paulo: Cultura Acadêmica, 2009.

PEREIRA, Rodrigo da Cunha. Uma principiologia para o direito de família. Revista RJLB, ano I (20 I5), n. I, p. I 87 I- | 893, Disponível em: < http://www.cidp.pt/ revistas/rjlb/20 I5/I/2015_0 I_I87|_|893.pdf>. Acesso em: 29 jul. 2019.

PIRES, Thiago José Teixeira. Princípio da Paternidade Responsável. [200 I , online]. Disponível em: <http://www.apmp.com.br/juridico/artigos/docs/200 I/I206_andreluiznogueiradacunha> $>$. Acesso em 30 jul. 2007

SANTOS, Eliane Araque. Criança e adolescente: sujeitos de direitos. 2006. Disponível em: <http://www.ibict.br/revistainclusaosocial/include/getdoc.php?i$\mathrm{d}=303 \&$ article $=57 \&$ mode $=$ pdf $>$. Acesso em: 29 jul. 2019 .

SARMENTO, Daniel. Dignidade da pessoa humana: conteúdo, trajetórias e metodologia. 2. ed. Belo Horizonte: Fórum, 2016.

SOUSA, Mônica Teresa Costa; WAQUIM, Bruna Barbieri. Do direito de família ao direito das famílias: a repersonalização das relações familiares no Brasil. Revista de Introdução Legislativa. Ano 52, n⿳ 205 jan./mar. 20I5, p. 7|-86. Disponível em: <https://wwwl2.senado.leg.br/ril/edicoes/52/205/ril_v52_n205_p7l.pdf>. Acesso em: 29 jul. 2019.

SOUZA, Alinne Bianca Lima; BELEZA, Mirna Carla Moreira; ANDRADE, Roberta Ferreira Coelho de. Novos arranjos familiares e os desafios ao direito de família: uma leitura a partir do Tribunal de Justiça do Amazonas. PRACS: Revista Eletrônica de Humanidades do Curso de Ciências Sociais da UNIFAP. Macapá, n. 5, dez. 2012, p. 105-119. Disponível em: < http://periodicos.unifap.br/index.php/ pracs > . Acesso em: 2 ago. 2019. 
SOUZA, Ivone M. C. Coelho de; DIAS, Maria Berenice. Famílias modernas: (Inter) Secções do afeto e da lei. Revista Brasileira de Direito Civil - RBDCivil Belo Horizonte, v. 2, n. 8, p. 62-69, jan./mar. 2001.

TARTUCE, Flávio Direito civil, v. 5: Direito de Família. I2. ed. rev., atual. e ampl. Rio de Janeiro: Forense, 2017.

\section{TOFFOLI, Dias. Voto vogal, proferido no julgamento do REXT $\mathrm{n}$.}

898.060/SC. Disponível em: <http://www.stf.jus.br/arquivo/cms/noticiaNoticiaStf/anexo/RE898060DT.pdf>. Acesso em: 3 ago. 2019.

VALADARES, Maria Goreth Macedo. Famílias recompostas. In: Congresso Brasileiro de Direito de Família 5, de 26.1 0 a 29.10.2005, Minas Gerais. Anais... Minas Gerais: IBDFAM, 2005, online. Disponível em: <http://www.ibdfam.org. br/publicacoes/anais/detalhes/7 I N\%20Congresso\%20Brasileiro\%20de\%20Direito\%20de\%20Fam\%C3\%ADlia>. Acesso em: 29 jul. 2019.

VECCHIATI, Paulo lotti. A tutela jurídica de travestis e transexuais que não se submeteram a cirurgia de transgenitalização. Em: FERRAZ, Carolina; LEITE, Glauber Salomão. Direito à diversidade (coords.). São Paulo: Atlas, 2015. 
Aprovado em: 30/04/2021 